\title{
Chemically Amplified Resists Containing Vinyllactam Derivatives
}

\author{
Jin-Baek Kim*, Min-Ho Jung, Jong-Ho Cheong, Jae-Young Kim \\ Cheol-Kyu Bok ${ }^{\dagger}$, Cha-Won Koh ${ }^{\dagger}$ and Ki-Ho Baik ${ }^{\dagger}$
}

\author{
Department of Advanced Materials Engineering, Korea Advanced Institute of Science and Technology \\ P.O. Box 201, Cheongryang, Seoul 130-650, Korea \\ † Memory R\&D Division, Hyundai Electronics Industries Co., Lid. San 136-1, Ami-ri, Bubal-ub, \\ Icheon-si, Kyoungki-do 467-701, Korea
}

\begin{abstract}
A new environmetally stable positive tone deep UV resist has been designed by incorporating basic units into a matrix polymer for stabilization toward airbone contaminants. Poly(3-(t-butoxycarbonyl)-1-vinylcaprolactam) (poly(BCVC)), and poly(3-(tbutoxycarbonyl)-1-vinylcaprolactam-co-t-butyl acrylate-co-hydroxystyrene) (poly(BCVC-coTBA-co-HOST)) were prepared and evaluated as potential deep UV photoresists. $0.2 \mathrm{rm}$ line/space patterns were obtained for these resist systems using a KrF excimer stepper (NA 0.55 ) with a dose of $25 \mathrm{~mJ} / \mathrm{cm}^{2}$. And these resists did not change pattern profile after 2 hours post exposure delay (PED) time in which ammonia concentration was $5 \mathrm{ppb}$. 3-(tButoxycabonyl)-1-vinyl-2-caprolactam (BCVC) unit as a basic moiety can not only solve the amine contamination problem effectively, bul also improve the resolution of the resists. BCVC unit reduces the diffusion of acid and it results in sharp contrast at the interface between the exposed and unexposed areas. Therefore, adding BCVC unit in matrix polymer leads to the stabilization of the pattern profile and higher resolution.

Keywords: vinyllactam, chemically amplified resist, environmental stability
\end{abstract}

\section{Introduction}

Continued advances in microelectronics and photolithography have accelerated the demand for photoresists with ever higher photosensitivity and resolution capabilities. The current goal of the microelectronic industry is to develop integrated circuits with minimum features of less than $0.25 \mu \mathrm{m}$. It is well recognized that to accomplish this goal, exposure tools which operate in the deep UV region $(190 \sim 300 \mathrm{~nm})$ of the spectrum will have to be used. Today, the best irradiation source which has been developed for use in this region is the $\mathrm{KrF}$ excimer laser emitting at $248 \mathrm{~nm}$. Accordingly, most recent developmental photoresist efforts are being directed specifically to respond to this exposure tool. To develop photoresists responsive to the $248 \mathrm{~nm}$ region, several major problems must be overcome. The first of these is the problem of achieving adequate sensitivity in this region of the electromagnetic spectrum. Therefore, there has been an increased interest in "chemical amplification" photoresist systems for deep UV photolithography. The basic idea utilizes the initial photogeneration of proton, followed by a subsequent (catalytic) chemical reaction to induce a change in solubility of the exposed area. $[1,2]$ While the combination of high throughput and high resolution offered by chemically amplified resist (CAR) is attractive, the drawback of this technology is the environmental and substrate dependency of these materials. Most CARs suffer from Ttopping and/or footing. They are easily affected by contaminations existing in the air and on the 
substrates, since resists of this type use a strong acid as a catalyst and become unstable to the environmental conditions. The contamination problem has been alleviates to some extents by purifying the enclosing atmosphere, [3] applying protective topcoat, [4] annealing the resists [5] and incorporating additives in resist formulation. $[6,7]$ However, there still exists a serious need for designing a chemical amplification resist which is insensitive to airborne contamination. Of those methods, we had an interest in the basic additives, typically amines, which do not only improve the delay time stability considerably but also act as acid scavangers especially for long range diffusion of acid molecules to increase contrast between exposed and unexposed areas. However, it remained a serious problem that the basic additives migrate to the surface of the resist film during a high temperature process.[8]

Here, we propose new resist systems composed of chemical amplification positive resists incorporating a basic unit in the matrix polymer chain. We describe the design concept of the new systems and prove that the new resist systems improve the post exposure delay (PED) stability.

\section{Experimental}

\subsection{Materials}

\subsubsection{Preparation of 1-Vinylcaprolactam} (VC)

Into 1.8 liter stainless steal autoclave was charged $350 \mathrm{~g}$ (3.1 mole) of E-caprolactam and $5.17 \mathrm{~g}(0.046 \mathrm{~mole})$ of potassium t-butoxide. The autoclave was purged three times with nitrogen at room temperature and then heated 120 130 ${ }^{\circ} \mathrm{C}$. Acetylene (partial pressure $65 \mathrm{psi}$ ) was added and the solution was agitated at a speed of $500 \mathrm{rpm}$. After $19 \mathrm{~h}$ of vinylation, the solution was fractionally distilled under 10 $\mathrm{mmHg}$. The product was obtained at 71 73 ${ }^{\circ} \mathrm{C}$ $/ 10 \mathrm{mmHg}$ (120 g, $34.2 \%)$ : IR (cm-1) 2932 (cyclic $\mathrm{CH}$ ), 1671 ( $\mathrm{C}=\mathrm{O}$ of amide), 1626 (vinyl)

\subsubsection{Preparation of 3-(t-Butoxycarbonyl)- 1-vinylcaprolactam (BCVC)}

A $2.5 \mathrm{M}$ solution of $\mathrm{n}$-butyllithium $(40 \mathrm{ml}$, $0.1 \mathrm{~mol}$ ) in hexane was added dropwise to a solution of diisopropylamine $(14 \mathrm{ml}, 0.1 \mathrm{~mol})$ in $40 \mathrm{ml}$ of anhydrous tetrahydrofuran (THF) at -
$78{ }^{\circ} \mathrm{C}$ with stirring under nitrogen atmosphere. After the addition was completed, the reaction was allowed to warm up to room temperature. The solution was cooled again to $-78{ }^{\circ} \mathrm{C}$, followed by dropwise addition of $30 \mathrm{ml}$ of an anhydrous THF solution of VC $(13.9 \mathrm{~g}, 0.1 \mathrm{~mol})$ and the resulting pale yellow solution was maintained at $-78{ }^{\circ} \mathrm{C}$ for $30 \mathrm{~min}$. Di-tertbutyldicarbonate (DtBDC) $(24 \mathrm{~g}, 0.11 \mathrm{~mol})$ in THF was added dropwise to the solution at -78 ${ }^{\circ} \mathrm{C}$. The reaction mixture was stirred for $2 \mathrm{~h}$ at $78{ }^{\circ} \mathrm{C}$ and then poured into diethyl ether.

The etheral layer was washed with water. The organic solution was dried and concentrated to give a pale yellowish syrup, which was purified by column chromatography on silica gel with ethyl acetate/hexane (1/3) as eluent. The desired fractions were combined, concentrated and dried in a vacuum oven. White powdery BCVC was obtained in a yield of $76 \%$ as sufficiently pure material without recrystallization: m.p. $55^{\circ} \mathrm{C}$; 1H-NMR $\left(\mathrm{CDCl}_{3}\right) \delta 7.0(1 \mathrm{H}, \mathrm{q},=\mathrm{CH}-), 4.5(2 \mathrm{H}$, $\left.\mathrm{m}, \mathrm{CH}_{2}=\right), 3.6(1 \mathrm{H}, \mathrm{m}, \mathrm{C} 3 \mathrm{H}), 3.4(2 \mathrm{H}, \mathrm{m}, \mathrm{C} 5 \mathrm{H})$, 1.4 2.1 (15H, m); IR (cm-1) 2936 (cyclic $\mathrm{CH})$, $1740(\mathrm{C}=\mathrm{O}$ of ester), $1665(\mathrm{C}=\mathrm{O}$ of amide), 1626 (vinyl), 1368 (t-butyl).

\subsection{Polymerization}

\subsubsection{Preparation of Poly(BCVC)}

A solution of $B C V C$ in benzene or dioxane that contained AIBN was heated at $65^{\circ} \mathrm{C}$ under vacuum in a sealed ampoule respectively. The polymer was precipitated in fresh petroleum ether and dried under vacuum.

\subsubsection{Preparation of Poly(ACOST-co-TBA- co-BCVC)}

A solution of ACOST, TBA and BCVC in toluene that contained AIBN was heated at 65 ${ }^{\circ} \mathrm{C}$ under vacuum in a sealed ampoule. The terpolymer was precipitated in fresh petroleum ether and dried under vacuum: ${ }^{1} \mathrm{H}-\mathrm{NMR}\left(\mathrm{CDCl}_{3}\right)$ $\delta \quad 6.7 \sim 6.2$ (br. $\mathrm{ArH}$ ), 4.7 and 3.5 and 3.3 (COCHCO and $\mathrm{N}-\mathrm{CH}$ and $\mathrm{N}-\mathrm{CH}_{2}$ of $\mathrm{BCVC}$ ), 2.23 (s, $\left.\mathrm{OCH}_{3}\right), 1.9 \sim 1.0\left(\mathrm{br},-\mathrm{C}\left(\mathrm{CH}_{3}\right)_{3}, \mathrm{CH}_{2}\right.$, and $\left.\mathrm{CH}\right)$.

\subsubsection{Preparation of Poly(HOST-co-TBA- co-BCVC)}

$15 \mathrm{ml}$ of $28 \%$ ammonia water was added to a solution of poly(ACOST-co-TBA-co-BCVC) (10 
g) in methanol. The reaction mixture was neutralized with acetic acid and poly(HOST-coTBA-co-BCVC) thus obtained was purified by precipitation in water, isolated by filtration, and dried in a vacuum oven at $50{ }^{\circ} \mathrm{C}(9.4 \mathrm{~g}, 92 \%$ yield): ${ }^{1} \mathrm{H}-\mathrm{NMR}\left(\mathrm{CD}_{3} \mathrm{OD}\right) \delta \quad 6.5 \sim 6.2(\mathrm{br}, \mathrm{ArH})$, 1.9 1.0 (br, $\mathrm{C}\left(\mathrm{CH}_{3}\right)_{3}, \mathrm{CH}_{2}$, and $\mathrm{CH}$ ), 1.4 0.9 (br, $-\mathrm{C}\left(\mathrm{CH}_{3}\right)_{3}, \mathrm{CH}_{2}$, and $\left.\mathrm{CH}\right)$.

\subsection{Thin Film Casting}

The resist solutions were prepared by dissolving matrix polymers $(11 \sim 14 \mathrm{wt} \%$ for solution) in propylene glycol methyl ether acetate. Triphenylsulfonium hexafluoroantimonate (TPSHFA) (5 7 wt\% for matrix polymers) as a photoacid generator, which was synthesized according to the literature, $[9,10]$ was mixed with the solutions. These solutions were filtered through a 0.45 and/or $0.2 \mu \mathrm{m}$ filter. From the solutions, $0.8 \sim 1 \mu \mathrm{m}$ films were obtained by spin-coating with $2500 \sim 3000 \mathrm{rpm}, 30$ seconds on $\mathrm{NaCl}$ plates for IR spectroscopy, on quartz cells for UV spectroscopy and on silicon wafers for lithographic evaluation.

\subsection{Lithographic Evaluation}

For the lithographic evaluation, the resist solutions were spin-coated at $2600 \mathrm{rpm}$ and the films on silicon wafers were pre-baked at 120 140 ${ }^{\circ} \mathrm{C}$ for $2 \mathrm{~min}$ to remove residual solvent. Exposures were carried out on $\mathrm{KrF}$ excimer stepper (0.55NA). For PED stability test, the exposed wafer was stored for 2 hours before PEB process in a cluster with chemical filter in which ammonia concentration is 5 ppb. The exposured films were post-exposure baked at 120 145 $\mathrm{C}$ for $3 \mathrm{~min}$ and developed in $\mathbf{2 . 3 8}$ wt\% TMAH aqueous solution.

\section{Results and Discussion}

\subsection{Preparation of Monomers and} Polymers

\subsubsection{Synthesis and Polymerization of BCVC}

Preparation of VC is generally carried out in two-stages where potassium t-butoxide is reacted with the $\varepsilon$-caprolactam to produce the corresponding $\varepsilon$-caprolactam salt and followed by vinylation of $\varepsilon$-caprolactam with acetylene.

The FT-IR spectrum of VC showed a vinyl absorption peak at $1626 \mathrm{~cm}^{-1}$. For introduction of the t-butoxycarbonyl (t-BOC) group to the 3position of $\mathrm{VC}, 1$-vinylcaprolactam enolate intermediate was generated by using lithium diisopropylamide (LDA) and then was reacted with di-t-butyl dicarbonate (DtBDC). The BCVC was obtained as a white powder and was sufficiently pure without recrystallization. Scheme 1 illustrates the preparation of VC and BCVC.

$$
\text { < Scheme } 1>
$$
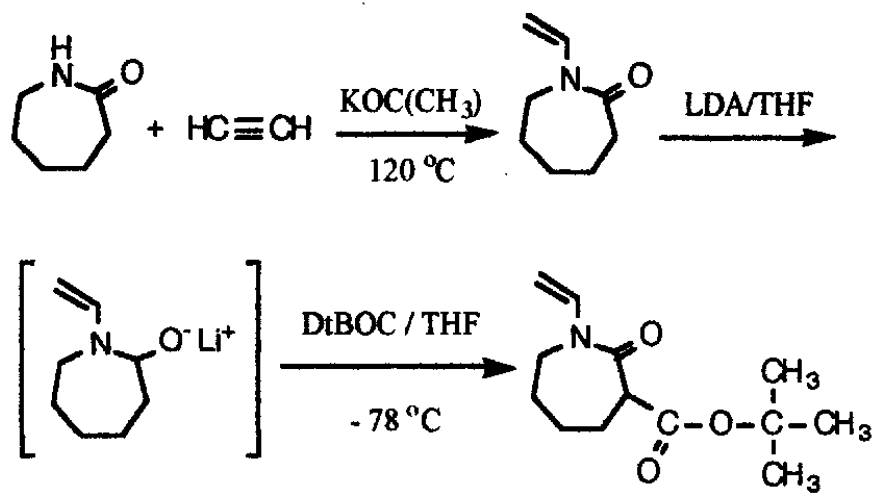

The polymerization results are shown in Table 1. The $\mathrm{t}-\mathrm{BOC}$ protected monomer was easily polymerized under radical polymerization condition. The FT-IR spectrum of the monomer showed a vinyl absorption at $1635 \mathrm{~cm}^{-1}$ which after polymerization disappeared completely. Bulk polymerization resulted in partial gel formation, but solution polymerization resulted in proper molecular weight for a resist. As shown in Table 1, the proper molecular weight was obtained when benzene or dioxane was used as a solvent. Molecular weight of the poly(BCVC) was controlled by the amount of the initiator and solvent used in the polymerization. 
Table 1. Radical Polymerization of BCVC

\begin{tabular}{lllllll}
\hline Solvent & $\begin{array}{l}\text { AIBNa } \\
(\mathrm{mol} \%)\end{array}$ & $\begin{array}{l}\mathrm{M} / \mathrm{Sb} \\
(\mathrm{g} / \mathrm{ml})\end{array}$ & $\begin{array}{l}\text { Time } \\
(\mathrm{h})\end{array}$ & $\begin{array}{l}\text { Conver- } \\
\text { sion } \\
(\%)\end{array}$ & $\begin{array}{l}\text { Inherent } \\
\text { viscosityc } \\
(\mathrm{dl} / \mathrm{g})\end{array}$ & $\begin{array}{l}\mathrm{Tg} \\
(\mathrm{oC})\end{array}$ \\
\hline Bulk(2a) & 1 & - & 12 & - & $*$ & - \\
Benzene(2b) & 1 & 1 & 12 & 88 & 0.32 & 179 \\
Benzene(2c) & 1 & 1.3 & 12 & 88 & 0.75 & 183 \\
Benzene(2d) & 1 & 2 & 12 & 90 & 1.20 & 190 \\
Dioxane(2e) & 1 & 1 & 12 & 91 & 0.30 & 174 \\
Dioxane(2f) & 0.5 & 2 & 12 & 90 & 0.42 & 181 \\
\hline
\end{tabular}

Polymerizations were carried out at $65^{\circ} \mathrm{C}$.

a Mol\% of the initiator AIBN to the total amount of monomer.

b $\mathrm{M} / \mathrm{S}$ is the ratio of the total weight of monomer to the volume of solvent.

c Inherent viscosities were measured at a concentration of $0.5 \mathrm{~g} / \mathrm{dl}$ in cyclohexanone at $25{ }^{\circ} \mathrm{C}$.

* Partial gel formation.

\subsubsection{Preparation of Poly(HOST-co-TBA)} and Poly(HOST-co-TBA-co-BCVC)

In the case of terpolymerization, the composition of the BCVC in terpolymer was very small compared with the fraction of the BCVC monomer which had been fed to the reaction (Table 2). In the IR spectra of the copolymer and terpolymers, the carbonyl bands in acetoxy group of ACOST and in t-butyl ester group of TBA were shown at $1765.6 \mathrm{~cm}^{-1}$ and $1725.5 \mathrm{~cm}^{-1}$. The amide carbonyl band of BCVC appeared at $1647.9 \mathrm{~cm}^{-1}$ with very low intensity and the absorption band of t-butyl ester carbonyl group was overlapped with those of ACOST and

The hydrolysis step using ammonium hydroxide was extremely selective. The t-butyl ester group of TBA and BCVC survived the basic reaction condition. From the IR spectrum of poly(HOST-co-TBA) the complete removal of the acetoxy group was confirmed. The phot ochemically-induced acid-catalyzed conversion of the ester to the carboxylic acid in the resist film can be monitored by following shrinkage of the absorptions at $1368 \mathrm{~cm}^{-1}$ and $1149 \mathrm{~cm}^{-1}$.

TBA.

Table 2. Radical Polymerization of Poly(ACOST-co-TBA) and Poly(ACOST-co-TBA-co-BCVC)

\begin{tabular}{cllccccc}
\hline $\begin{array}{c}\text { Sample } \\
\#\end{array}$ & $\begin{array}{c}\text { Molar feed } \\
\text { ratioa } \\
(1: \mathrm{m}: \mathrm{n})\end{array}$ & $\begin{array}{c}\text { AIBNb } \\
(\mathrm{mol} \%)\end{array}$ & $\begin{array}{c}\mathrm{M} / \mathrm{Sc} \\
(\mathrm{g} / \mathrm{mol})\end{array}$ & $\begin{array}{c}\text { Time } \\
(\mathrm{hr})\end{array}$ & $\begin{array}{c}\text { Conversion } \\
(\%)\end{array}$ & $\begin{array}{c}\text { Inherent } \\
\text { viscosityd }\end{array}$ & $\begin{array}{c}\text { Composition of } \\
\text { polymere } \\
(1: \mathrm{m}: \mathrm{n})\end{array}$ \\
\hline $4 \mathrm{a}$ & $10: 7: 0$ & 0.2 & 2.5 & 20 & 82 & 0.53 & $62.0: 38.0: 0.0$ \\
$4 \mathrm{~b}$ & $10: 6: 0.5$ & 0.2 & 2.5 & 20 & 80 & 0.51 & $64.3: 35.0: 0.7$ \\
$4 \mathrm{c}$ & $10: 6: 1$ & 0.2 & 2.5 & 20 & 81 & 0.49 & $63.6: 35.0: 1.4$ \\
$4 \mathrm{~d}$ & $10: 7: 3$ & 0.2 & 2.5 & 20 & 72 & 0.46 & $58.1: 59.3: 2.6$ \\
\hline
\end{tabular}

a Polymerization was carried out at $65^{\circ} \mathrm{C}(1:$ ACOST; $m:$ TBA; $n: B C V C)$.

$\mathrm{b}$ Mol\% of the initiator AIBN to the total amounts of monomer.

c $\mathrm{M} / \mathrm{S}$ is the ratio of the total weight of monomer to the weight of toluene.

$\mathrm{d}$ Inherent viscosities were measured at a concentration of $0.5 \mathrm{~g} / \mathrm{dl}$ in DMF at $25^{\circ} \mathrm{C}$.

e The composition of polymer is the mole ratio of monomers in polymer. 
The compositions of the copolymer and terpolymers can be calculated from the IH-NMR spectrum and TGA plots. According to the $1 \mathrm{H}$ NMR spectra of poly(HOST-co-TBA) and poly(HOST-co-TBA-co-BCVC), the complete removal of acetoxy group can be confirmed again by the fact that the single peak of three protons of acetoxy group at $2.23 \mathrm{ppm}$ disappeared.

\subsection{Physical Properties of the Resist Polymers}

\subsubsection{Thermal Analysis of Poly(BCVC)}

Before imaging tests were carried out, the acid catalyzed cleavage of the protected polymer was studied using TGA and FT-IR. The TGA thermogram of poly(BCVC) shown in Figure 1a indicates that poly(BCVC) possesses good thermal stability up to 200 C. At that temperature, a rapid weight loss took place due to evolution of isobutylene and carbon dioxide resulting from spontaneous thermolysis of the tBOC groups. Poly(BCVC) were converted to poly(N-vinylcaprolactam) by thermal deprotection of the $t-B O C$ groups as shown in Scheme 2.

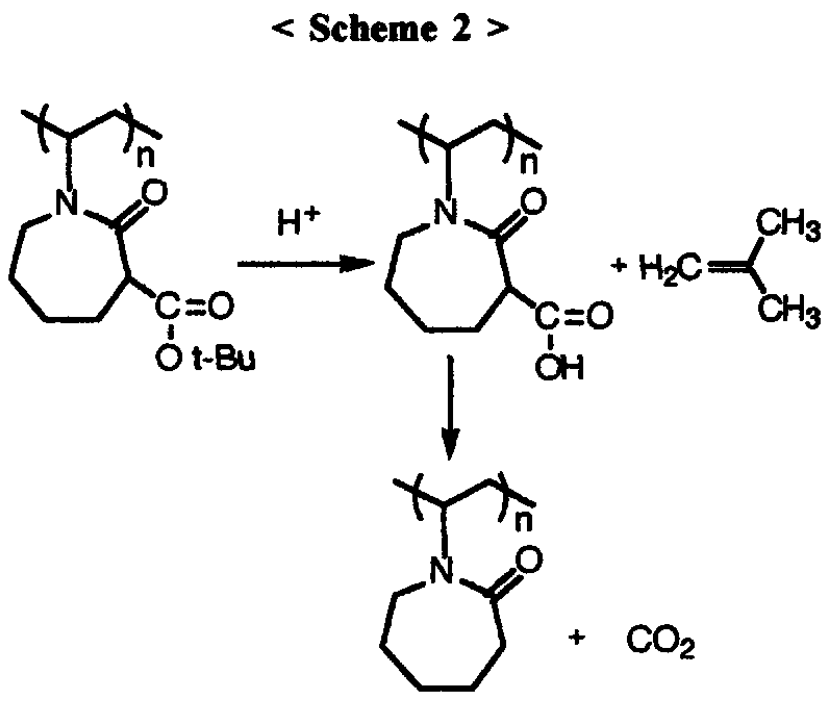

In the abscence of acid, the deprotection of the t-BOC groups of poly(BCVC) occurred above $220^{\circ} \mathrm{C}$ whereas, in the presence of a generated acid, the cleavage of the t-butyl groups of poly(BCVC) was found to begin around $60^{\circ} \mathrm{C}$ as shown in Figure $1 \mathrm{~b}$ and completed at about 120 $c$, and then the carbon dioxide was evolved subsequently.
The thermal deprotection of the $t-B O C$ groups of poly(BCVP) resulted in almost the same weight loss of $42 \mathrm{wt} \%$ with or without a generated acid, which corresponds to the theoretically calculated weight loss due to the evolution of carbon dioxide and isobutylene from the polymer.

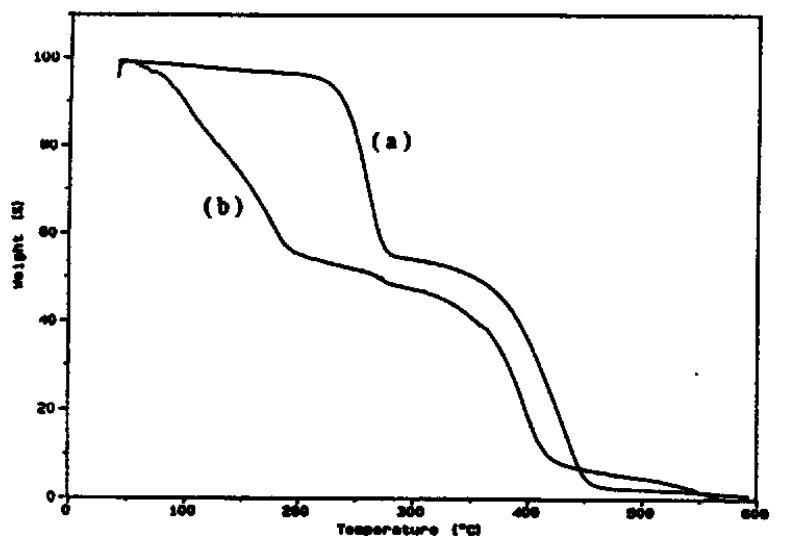

Figure 1. Comparision of TGA thermograms of poly(BCVC) containing $7 \mathrm{wt} \%$ of TPSHFA before (a) and after (b) UV exposure

\subsubsection{Thermal Analysis of Poly( HOST-co- TBA) and Poly(HOST-co-TBA-co-BCVC)}

Thermal properties of the copolymer and terpolymers are shown in Table 3 . The glass transition temperature of Poly( HOST-co-TBA) or Poly( HOST-co-TBA-co-BCVC) was about 165 C.

The onset temperature of the thermal deprotection of the polymers was ca. $180{ }^{\circ} \mathrm{C}$ and the deprotection completed at about $250{ }^{\circ} \mathrm{C}$. But the shape of two step cleavage of the BCVC units in the TGA thermogram was not so clear.

\subsubsection{Acid-Catalyzed Deprotection Studies by FT-IR spectrophotometer}

In a typical experiment for solid-state photolysis, solutions of poly(BCVC) containing $7 \mathrm{wt} \%$ of a photoacid generator, triphenylsulfonium hexafluoroantimonate, was spun on a $\mathrm{NaCl}$ pellet. FT-IR spectra were recorded as shown in figure $2 a$. The film was exposed for $20 \mathrm{sec}$ using a $450 \mathrm{~W}$ high-pressure mercury lamp with a narrow-band $250 \mathrm{~nm}$ interference filter $\left(20 \mathrm{~mJ} / \mathrm{cm}^{2}\right)$ and baked at 125 ${ }^{\circ} \mathrm{C}$ (figure $2 \mathrm{~b}$ ) and $160^{\circ} \mathrm{C}$ (figure 2c) 
Table 3. Thermal properties of Poly(HOST-co-TBA) and Poly(HOST-co-TBA-co-BCVC)

\begin{tabular}{cllll}
\hline $\begin{array}{c}\text { Composition of polymer } \\
(\mathrm{l}: \mathrm{m}: \mathrm{n}){ }^{\mathrm{a}}\end{array}$ & $\begin{array}{l}\mathrm{Tg}^{\mathrm{b}} \\
\left({ }^{\circ} \mathrm{C}\right)\end{array}$ & $\begin{array}{l}\mathrm{Tdp}^{\mathrm{c}} \\
\left({ }^{\circ} \mathrm{C}\right)\end{array}$ & $\begin{array}{l}\mathrm{T}^{\mathrm{d}} \mathrm{dp} \\
\left({ }^{\circ} \mathrm{C}\right)\end{array}$ & $\begin{array}{l}\text { Mass losse } \\
(\%)\end{array}$ \\
\hline $62.0: 38.0: 0.0$ & 165.1 & 184 & 135 & 16.5 \\
$64.3: 35.0: 0.7$ & 164.7 & 181 & 131 & 15.6 \\
$63.6: 35.0: 1.4$ & 165.2 & 182 & 136 & 16.1 \\
$58.1: 59.3: 2.6$ & 165.5 & 187 & 136 & 16.9 \\
\hline
\end{tabular}

a $1:$ HOST, $m:$ TBA, $n:$ BCVC

b $\mathrm{Tg}$ of polymers measure by DSC in the second run at a heating rate of $10^{\circ} \mathrm{C} / \mathrm{min}$.

c Tdp : onset deprotection temperature of copolymer and terpolymers measured by TGA

d T'dp : onset deprotection temperature of copolymer and terpolymers after exposure measured by TGA

e Measured in wt $\%$ by TGA

In a FT-IR spectrum (Figure 2a), the absorption peaks of $1733 \mathrm{~cm}^{-1}, 1642 \mathrm{~cm}^{-1}, 1368$ $\mathrm{cm}^{-1}$ corresponded to esteric carbonyl, amide carbonyl and t-butyl group, respectively.

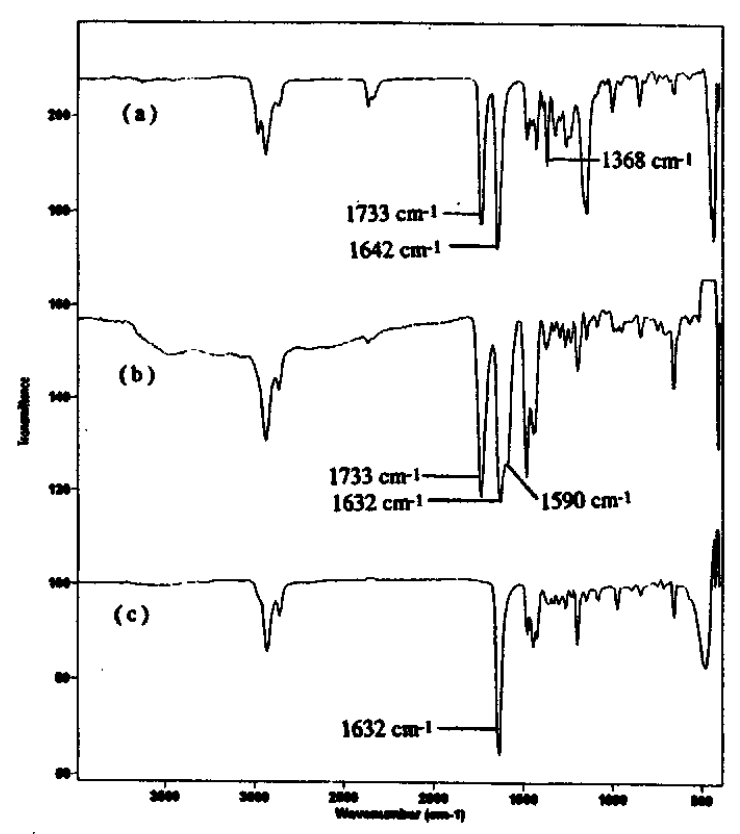

Figure 2. Infrared spectral change of poly(BCVC) before (a) and after (b), (c) exposure (b: PEB at $125^{\circ} \mathrm{C}$ for $3 \mathrm{~min}, \mathrm{c}$ : PEB at $160{ }^{\circ} \mathrm{C}$ for $3 \mathrm{~min}$ )

Figure $2 b$ showed that the cleavage reaction resulted in disappearance of the t-butyl group and formation of the carboxylic acid on the polymer. The C-H symmetric bending band of $t-$ butyl group at about $1368 \mathrm{~cm}^{-1}$ disappeared after cleavage while formation of new broad band corresponded to the carboxylic $\mathrm{O}-\mathrm{H}$ stretching at about $3500 \mathrm{~cm}^{-1}$.

In addition, the absorption bands of amide carbonyl groups were splited into two. Amide carbonyl peak of the poly(1-vinyl-2caprolactam carboxylic acid) was shown at about $1590 \mathrm{~cm}^{-1}$ and the other peak $\left(1632 \mathrm{~cm}^{-1}\right)$ was amide carbonyl peak of the poly(1-vinyl-2caprolactam). Then, Figuire $2 \mathrm{c}$ showed that the carbon dioxide was evolved and poly(BCVC) was converted to poly(1-vinyl-2-caprolactam). The photoacid-catalyzed cleavage of pendant t-butyl groups in the exposed area resulted in a large change of polarity of the polymer.

In case of the other BCVC containing polymers, it showed the same result as poly(BCVC).

\subsubsection{Transmittance}

Table 4 shows the UV absorbance of the polymers. From the UV spectra, poly(BCVC) resist film displayed excellent transparency in the $220 \sim 300 \mathrm{~nm}$ region. The major contributor to the absorption at these wavelengths is the onium salt photoacid generator. Upon irradiation and subsequent post exposure baking (PEB), the absorption band shifted to slightly longer wavelengths. The absorption coefficients for poly(BCVC) at 248 $\mathrm{nm}$ in the solid state were determined to be $0.045 \mu \mathrm{m}^{-1}(\mathrm{~T}=90 \%)$. Moreover the other polymers that contained BCVC have excellent transparency at $248 \mathrm{~nm}$ (Table 4). 
Table 4. UV Absorbance of resist polymers at $248 \mathrm{~nm}$

\begin{tabular}{|c|c|c|c|}
\hline \multirow[t]{2}{*}{ Polymers } & \multirow[t]{2}{*}{$\begin{array}{l}\text { Absorbance of } 1 \mu \mathrm{m} \\
\text { thickness resist film }\end{array}$} & \multicolumn{2}{|c|}{$\begin{array}{l}\text { Absorbance of } 1 \mu \mathrm{m} \text { thickness resist } \\
\text { film with } 5 \mathrm{wt} \% \text { TPSHFA }\end{array}$} \\
\hline & & Before exposure & After exposure ${ }^{\mathfrak{c}}$ and $\mathrm{PEB}^{\mathrm{C}}$ \\
\hline poly(BCVC) & 0.045 & 0.211 & 0.233 \\
\hline poly(HOST-co-TBA)a & 0.119 & 0.315 & 0.325 \\
\hline $\begin{array}{l}\text { poly(HOST-co-TBA-co- } \\
\text { BCVC) }\end{array}$ & 0.107 & 0.309 & 0.312 \\
\hline
\end{tabular}

\subsection{Lithographic Evaluation}

In chemically amplified resist systems, holding time between exposure and postexposure baking often affects the sensitivity and the resolution. We examined PED stability on the poly(BCVC) resist system. In this experiment, resist films were left in air without any treatment. Exposure characteristic curves with different PED times are shown in Figure 3.

The contrast of this resist was not deteriorated with the PED time. The scanning electron microscope photographs of patterns after $2 \mathrm{~h}$ delay time are shown in Figure 4.

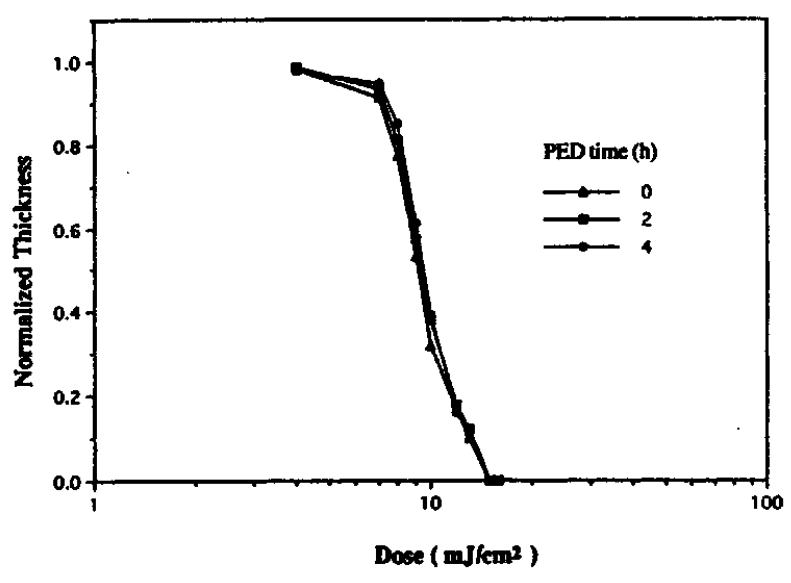

Figure 3. PED effect on exposure characteristic curves of poly(BCVC) resist (PEB : $125^{\circ} \mathrm{C}$, $3 \mathrm{~min})$

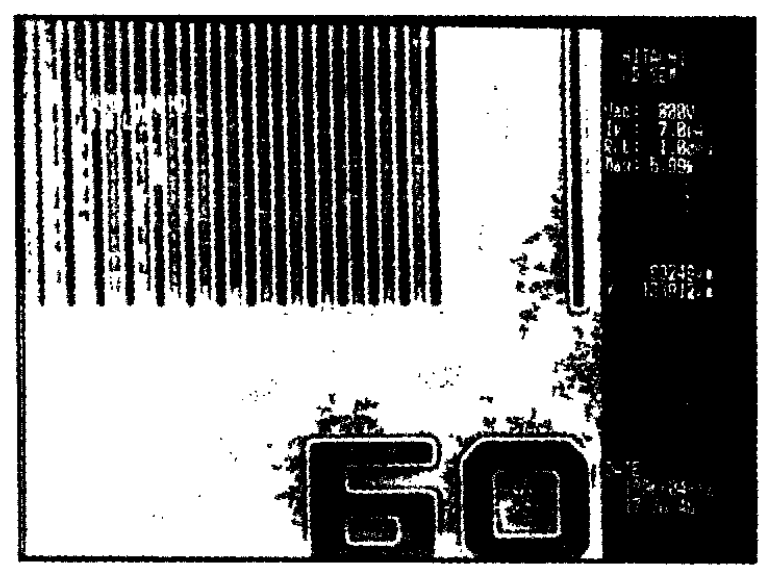

Figure 4. SEM photograph of $0.6 \mu \mathrm{m} \mathrm{L/S} \mathrm{positive}$ images formed of poly(BCVC) resist at 22 $\mathrm{mJ} / \mathrm{cm}^{2}$ (PED time : 2h)

In the case of poly(HOST-co-TBA-co$\mathrm{BCVC}$ ) resist system, figure 5 and 6 show the SEM photographs of patterns of poly(HOSTco-TBA) and poly(HOST-co-TBA-co-BCVC) for immediate PEB and PEB after $30 \mathrm{~min}, 2 \mathrm{~h}$ delay time. Conventional photoresist, poly(HOST-co-TBA) resist system shows T-top and do not develope in TMAH solution after 30 min PED time. However, the pattern profile of poly(HOST-co-TBA-co-BCVC) resist system is not deteriorated and T-top is not observed.

The new resist systems containing vinyllactam derivatives were found to possess desirable properties such as PED stability, thermally stablility and high resolution. 


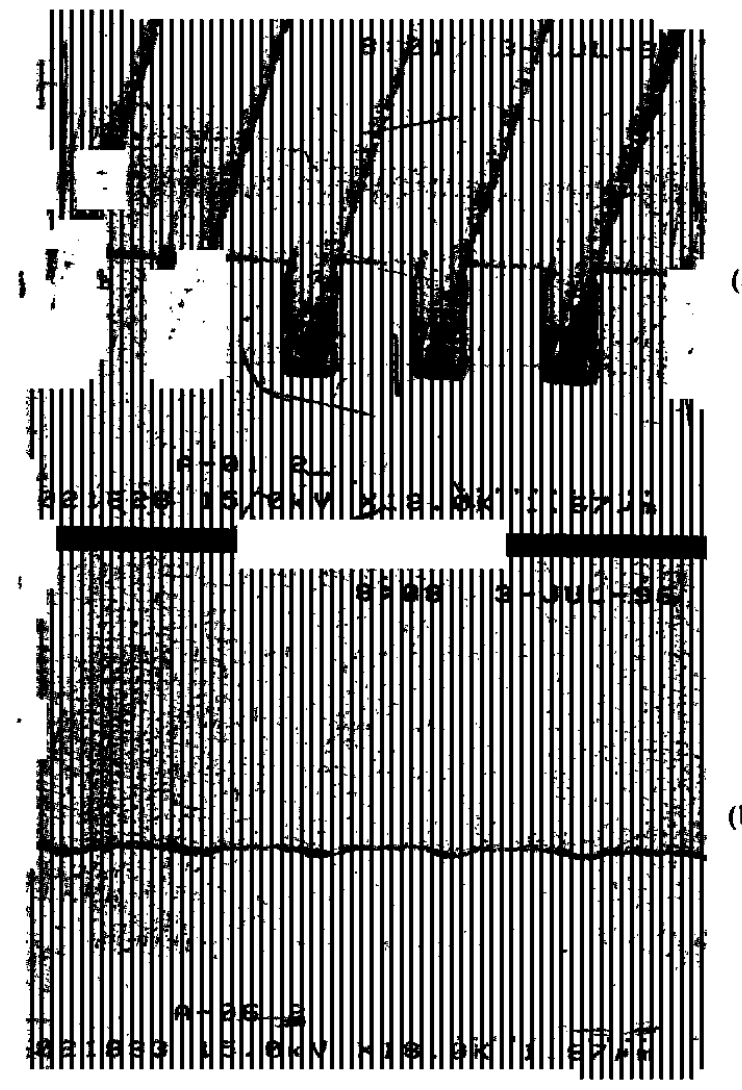

Figure 5. SEM photographs of positive images formed of poly(HOST-co-TBA) (4a) resist at 15 $\mathrm{mJ} / \mathrm{cm}^{2}$ (a : no PED time, $\mathrm{b}: 30 \mathrm{~min}$ PED time)

\section{Conclusion}

New resist systems were proposed in order to improve the environmental stability. We prepared new deep UV photoresist materials which have basic moiety in the matrix polymer. Poly(3-(t-butoxycarbonyl)-1 -vinylcaprolact am) and poly (3-(t-but oxy carbony 1$)-1$-vinyl caprolact am-co-t-but ylacrylat e-co-h ydroxy styrene) were synthesized and evaluated as potential deep UV photoresists. The synthesized polymers have excellent transmittance at 248 nm (absorbance $=0.018 \sim 0.041 \mu \mathrm{m}-1)$ ). In addition, the synthesized polymers possess good thermal stability up to $200{ }^{\circ} \mathrm{C}$ and high glass transition temperatures (140 195 $\left.{ }^{\circ} \mathrm{C}\right)$. And we examine post-exposure delay (PED) stability on the synthesized polymer resist systems.As a result of exposure characteristic curves with different PED times, the contrast of this resist was not deteriorated with the PED time.

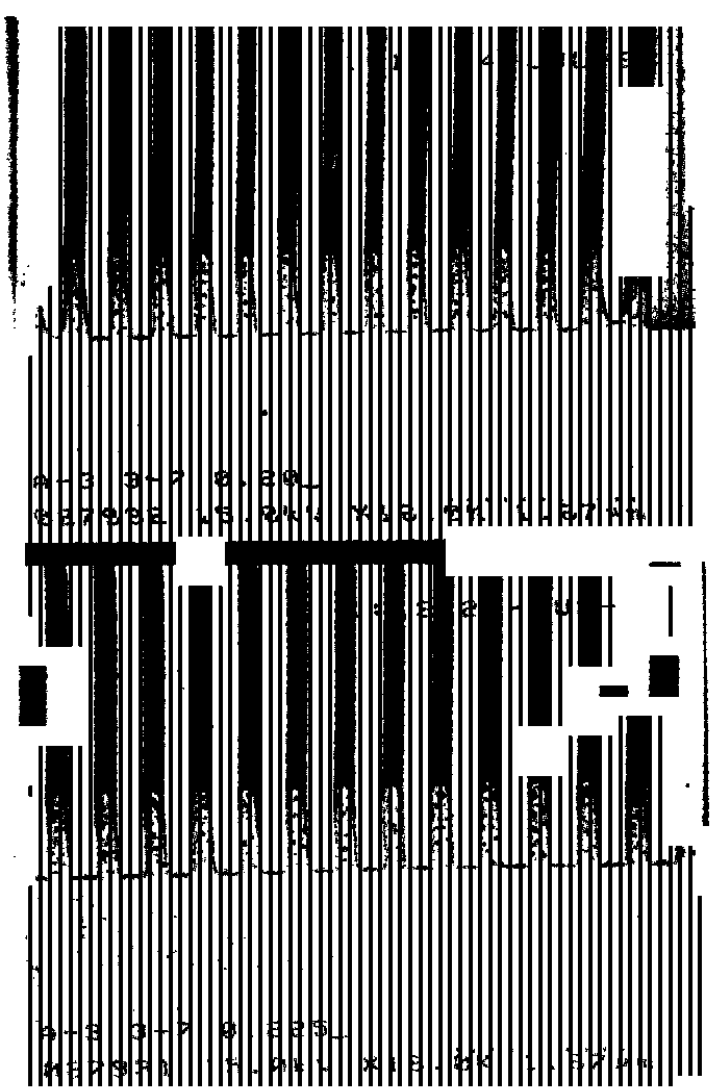

Figure 6. SEM photographs of positive images formed of poly(HOST-co-TBA-co-BCVC) (4d) resist at $24 \mathrm{~mJ} / \mathrm{cm}^{2}$ (PED time : $2 \mathrm{~h}$ )

We obtained $0.2 \mu \mathrm{m}$ line/space patterns. The pattern profile is not deteriorated and T-top is not observed with $2 \mathrm{~h}$ PED time. By introducing basic units into a matrix polymer, this new resist system can prevent basic additives from migrating to the surface.

We knew that the new resist systems have desirable properties such as high transparency in deep UV region, facile deprotection, and proper sensitivity. And we confirmed improvement of environmental stability by introducing basic unit. The basic additives were employed to play dual roles: 1) improvement of environmental stability and 2) reduction of the diffusion of photogenerated acid to unexposed area. The quantitative study of the diffusion of acid in the presence of basic unit will be carried out to determine the proper basic unit composition in the resist polymer, which satisfies the requirements of suitable sensitivity, 
improvement of PED stability, and reduction of diffusion of acid for fine pattern.

\section{References}

1. H. Ito and C. G. Willson. "Polymers in Electronics", ACS Symposium Series No. 242, Washington, DC (1984), p 11.

2. J. V. Crivello, J. L. Lee and D. A. Gonlon. J. Polym. Sci.; Polym. Chem. Ed. 25 (1987) 3293. 3. S. A. McDonald, N. J. Cleeak, H. R. Wendt, C. G. Willson, C. D. Snyder, C. J. Knors, N. B. Deyoe, J. G. Maltables, J. R. Morrow, A. E. McGuire, and S. J. Holmes, Proc. SPIE, 1446 (1991) 2.

4. O. Nalamsu, M. Cheng, A. G. Timko, V. Pol, E. Reichmanis, and L. F. Thompson, $J$.
Photopolym. Sci. Technol., 4 (1991) 299.

5. H. Ito, G. Breyta, D. Hofer, R. Sooriyakumaran, K. APetrillo, and D. J. Seeger, J. Photopolym. Sci. Technol., 7 (1994) 433.

6. H. Roschert, K. J. Przybilla, W. Spiess, H. wingenroth, and G. Pawlowski, Proc. SPIE., 1672 (1993) 33.

7. D. J. H. Funhoff, H. Binder, and R. Schwalm, Proc. SPIE., 1672 (1992) 46.

8. Y. Kawai, A. Otaka, J. Nakamura, A. Tanaka, and T. Matsuda, J. Photopolym. Sci. Technol., 8 (1995) 535.

9. J. L. Dekar, and N. P. Hacker. J. Am. Chem. Soc. 112 (1990) 6004.

10. J. V. Crivello, and J. H. W. Lam. J. Org. Chem. 43 (1978) 3055. 